\title{
Relationship between cognition and gait performance in older adults receiving physical therapy interventions in the home
}

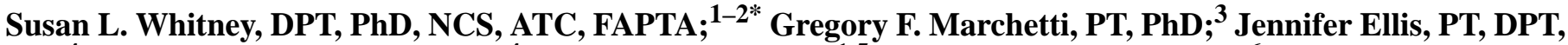 \\ MS; ${ }^{4}$ Laurie Otis, PT, MBA, MHA; ${ }^{4}$ Faisal Asiri, PT, PhD; ${ }^{1,5}$ Ahmad Alghadir, PT, PhD ${ }^{6}$ \\ Departments of ${ }^{1}$ Physical Therapy and ${ }^{2}$ Otolaryngology, University of Pittsburgh, Pittsburgh, PA; ${ }^{3}$ Department of \\ Physical Therapy, Duquesne University, Pittsburgh, PA; ${ }^{4}$ Gentiva Health Services, Atlanta, GA; ${ }^{5}$ Department of Reha- \\ bilitation Sciences, King Khalid University, Abha, Saudi Arabia; ${ }^{6}$ Rehabilitation Research Chair, King Saud Univer- \\ sity, Riyadh, Saudi Arabia
}

\begin{abstract}
Persons undergoing physical therapy home services often have difficulty with mobility and gait. The purpose of this study was to determine whether there was a relationship between gait and a rating of cognitive functioning in persons undergoing home-care physical therapy services. Patients over the age of $65(n=11,601)$ seen by a home-care agency between 2007 and 2008 were included in the retrospective analysis, and 10,953 (mean +/- standard deviation age $83.2+/-7.1 ; 31 \%$ ) met the criteria of being able to ambulate independently or with an assistive device. All patients attempted to perform the modified Clinical Test of Sensory Integration and Balance plus either the Performance Oriented Measurement Assessment (POMA) or the Dynamic Gait Index (DGI). Mental function was scored as part of the Outcome and Assessment Information Set. A multivariate model with adjustment for age and sex identified gait performance as measured by the DGI to be independently associated with the likelihood that a patient required cognitive prompting $(p=0.03)$. Both the DGI and POMA scores were independently associated with requiring assistance/dependence with cognitive tasks. There was a strong relationship between cognition and gait performance in persons undergoing physical therapy interventions in the home. Changes in gait may be related to cognitive decline.
\end{abstract}

Key words: balance, cognition, falls, gait, home care, measurement, older adults, Outcome and Assessment Information Set (OASIS), physical therapy, residence.

\section{INTRODUCTION}

There is emerging data about the relationship between peoples' mental capabilities and their ability to ambulate. Recently, in a large study of older Mexican Americans, early mental decline was associated with changes in gait speed [1]. Those that walked slower had greater declines on the Mini-Mental State Examination (MMSE) over a $7 \mathrm{yr}$ period. Nondisabled older adults who live in the community walked longer distances on the 6 min walk test when compared with those living in an assisted living situation [2]. Overall, gait speed has been shown to be related to long-term survival in persons over the age of 65 [3]. In at-risk older adults, loss of

Abbreviations: $\mathrm{ANCOVA}=$ analysis of covariance, $\mathrm{CI}=$ confidence interval, DGI $=$ Dynamic Gait Index, $\mathrm{mCTSIB}=$ modified Clinical Test of Sensory Integration and Balance, MCID = minimal clinically important difference, MMSE $=$ Mini-Mental State Examination, MRI $=$ magnetic resonance imaging, OASIS = Outcome and Assessment Information Set, OR = odds ratio, POMA $=$ Performance Oriented Measurement Assessment.

*Address all correspondence to Susan L. Whitney, DPT, PhD, NCS, ATC, FAPTA; Professor in Physical Therapy, University of Pittsburgh, 6035 Forbes Tower, Pittsburgh, PA 15260; 412-383-6642; fax: 412-648-5970.

Email: whitney@pitt.edu

http://dx.doi.org/10.1682/JRRD.2012.06.0119 
functional mobility was related to slower scores on a $400 \mathrm{~m}$ timed gait task [4].

Cognitive function has previously been related to fall risk in long-term care environments [5]. Although cognitive loss generally makes rehabilitation more difficult for the healthcare team, Morghen et al. recently reported that persons with moderate to severe cognitive impairments were often able to ambulate independently $1 \mathrm{yr}$ after total hip replacement [6].

Physical therapy intervention in the home appears to have a positive effect on persons receiving care in the home. An intensive $10 \mathrm{wk}$ ( 2 times per wk) program of progressive resistive exercises in the home 6 mo post hip fracture discharge produced changes in gait speed compared with a control group that were maintained at the 3 mo follow-up visit [7]. Home-based walking programs in older persons living in the community have supported changes in quality of life and a shuttle stamina walk test [8]. The location where seniors ambulate and the intensity of the walking program have been related to cognitive status, with higher-functioning seniors ambulating more outdoors in parks and less in shopping malls [9]. Therefore, cognitive function and gait performance appear to be related $[1,5]$.

Rehabilitation in the home-care setting is designed to safely reintroduce people to their community. The Outcome and Assessment Information Set (OASIS) is the standardized tool used in the United States at patient intake to attempt to monitor care in home-care agencies and to adjust payments to account for differences in patients [10]. The purpose of this study was to determine whether there was a relationship between cognitive functioning in a large home-care agency Medicare OASIS database and observed gait/balance performance. This article attempts to describe the relationship between the OASIS measure of cognition and standardized measures of gait performance. This relationship has not previously been described in the home-care practice setting. Standardized measures of gait are not commonly performed in the home-care setting, but are often used to document gait impairments in community-living older persons.

\section{METHODS}

All persons over the age of 65 seen by Gentiva Health Services, Atlanta, Georgia, between 2007 and 2008 were included, with 10,953 (mean \pm standard devia- tion age $=83.2 \pm 7.1 \mathrm{yr}$; range: $65-106 \mathrm{yr}, 31 \% \mathrm{men}$ ) meeting the criteria of being able to ambulate independently or at least with assistance and who were indicated at referral to be at increased risk of falling (Table 1). Patients with a history of falls in the previous $12 \mathrm{mo}$ and/ or one or more modifiable fall risk factors were included in the analysis. The definition of modifiable fall risk factor included home hazards [11-12], polypharmacy, psychotropic medication use [11], lower-limb weakness [11], gait and mobility dysfunction, impaired balance [13], dizziness [14], orthostatic hypotension, impaired sensation or vision [11], and sedative hypnotic use [11,15].

Gait and balance data were collected by physical therapists in each person's living environment. A fallreduction education program $(19.5 \mathrm{~h})$ was completed by all physical therapists that collected the gait and balance data. Clinicians were taught how to systematically examine and intervene with persons at risk for falling in order to attempt to modify the risk factor(s). Major educational content included a review of balance and dizziness and examination and treatment of persons with vestibular disorders and peripheral neuropathy; tools to assess risk of falling in older adults were also included.

All physical therapists participated in evaluation, intervention, and documentation experiences, and their clinical records were all reviewed for accuracy prior to data collection to ensure that they were all inputting the data correctly and were familiar with the data entry system. During the home-care educational program, physical

\section{Table 1.}

Characteristics of sample: type of residence, Outcome and Assessment Information Set (OASIS) cognition, and ambulation rating (total $N=10,953$ ).

\begin{tabular}{|c|c|c|}
\hline Characteristic & Level & $n(\%)$ \\
\hline \multirow[t]{5}{*}{ Residence* $^{*}$} & Patient Home & $7,135(65.1)$ \\
\hline & Family Residence & $1,226(11.2)$ \\
\hline & Board Home or Rented Room & $101(0.9)$ \\
\hline & Board/Care or Assisted Living & $2,440(22.3)$ \\
\hline & Other & $51(0.5)$ \\
\hline \multirow[t]{4}{*}{ Cognition $^{\dagger}$} & Independent & $5,867(53.6)$ \\
\hline & Prompting Required & $3,364(30.7)$ \\
\hline & Some Assistance & $1,360(12.4)$ \\
\hline & Considerable Assistance & $362(3.3)$ \\
\hline \multirow[t]{3}{*}{ Ambulation } & Independent & $163(1.5)$ \\
\hline & Independent with Device & $5,565(50.8)$ \\
\hline & Assistance Required & $5,225(47.7)$ \\
\hline $\begin{array}{l}{ }^{*} \text { OASIS M0300. } \\
{ }^{\dagger} \text { OASIS M0560. } \\
\text { *OASIS M0700. }\end{array}$ & & \\
\hline
\end{tabular}


therapists were trained and tested on how to systematically use the Performance Oriented Measurement Assessment (POMA) [16], the Dynamic Gait Index (DGI) [17-18], and the modified Clinical Test of Sensory Integration and Balance (mCTSIB) [19-20]. The therapists were instructed to perform the MCTSIB and at least one of the two gait measures during the physical therapy intake as part of the home-care company's ongoing plan to require outcome measures as part of their quality improvement plan. All data were de-identified through an independent broker and were entered on a secure server for analysis.

The POMA is a 28-point measure that assesses balance and gait and that is commonly used with older persons. The POMA consists of 12 points related to gait and 16 points related to balance, with scores of 19 or less suggesting high fall risk. Patients are asked to walk and are tested on sitting and standing static and dynamic balance activities, such as the sternal nudge, $360^{\circ}$ turn, sit to stand transitions, and eyes-closed standing. Equipment use is minimal and includes a stopwatch, armless hard chair, and a $4.57 \mathrm{~m}$ walkway.

The DGI has eight different aspects of gait function with a total point value of 24 . Patients are asked to walk down a walkway, walk at different speeds, walk and stop quickly, walk while turning their head up and down and right and left, walk over and around a box, and walk up and down a set of steps. Scores of 19 or less have been related to falls in older persons [21].

The mCTSIB assesses standing balance using the Romberg eyes open and eyes closed conditions, as well as the same conditions while subjects stand on a foam pad for $30 \mathrm{~s}$. All three measures, the POMA, DGI, and mCTSIB, have been previously used to record balance function in older people [16-19,22-24].

Physical therapists and nurses with at least $1 \mathrm{yr}$ of professional experience were also trained in collection of OASIS data. Cognition on the OASIS (M0560) was rated as independent, requires prompting, some assistance, and considerable assistance; in addition, level of assistance for ambulation was rated as walking with assistance, independent with an assistive device, or independent in ambulation for all patients. The location where the patient was currently living was also retrieved from the OASIS database.

\section{DATA ANALYSIS}

The association between cognition and gait performance was tested using a multivariate analysis of covariance (ANCOVA) to compare mean DGI and POMA scores at the beginning of rehabilitation between four cognitive function groups as measured by OASIS M0560 (independent, requires prompting, some assistance, and considerable assistance). Mean DGI and POMA scores were adjusted for the potential effects of age, sex, and static balance function (number of successfully completed mCTSIB conditions) within cognitive function groups. Adjusted mean DGI and POMA scores were compared between cognitive function groups using a Bonferroni adjustment for multiple comparisons and a type I error rate of $p<0.05$. A comparative analysis was performed to compare patient groups who received clinical gait analysis with the DGI and/or POMA with those who were not assessed upon initial evaluation.

Nominal regression models were used to establish the association between gait, mobility and balance performance, and cognitive function across two levels of cognitive assistance (prompting and any assistance) relative to cognitive independence. Likelihood of cognitive prompting or assistance relative to independence was estimated (using maximum likelihood estimate) with odds ratios (ORs) and 95 percent confidence intervals (CIs) on the basis of the univariate association with gait and balance performance measures. All nominal regression models were adjusted for age and sex. A type I error rate of 0.05 was used to determine significance. Data were analyzed using PASW Statistics, version 18.0. (IBM Corp; Armonk, New York).

\section{RESULTS}

The majority of subjects $(65.1 \%)$ were residing in their own homes, were rated at the independent level for cognitive function $(53.6 \%)$, and were ambulating independently at least with an assistive device (52.3\%) based on OASIS item M0560 (Table 1). The DGI and/or POMA were completed upon evaluation by physical therapists for $9,258(84.5 \%)$ of the patients who met the study inclusion criteria (DGI $n=3,877$, POMA $n=$ 6,154 , both measures $n=773$ ).

Descriptions of patient age, sex, living situation, gait, and standing balance performance by level of cognitive 
Table 2.

Subject characteristics and gait and static balance performance for cognitive function groups as defined by Outcome and Assessment Information Set (OASIS): Dynamic Gait Index (DGI), Performance Oriented Measurement Assessment (POMA), and modified Clinical Test of Sensory Integration and Balance (mCTSIB) scores for subjects receiving gait/balance assessment $(n=9,258)$.

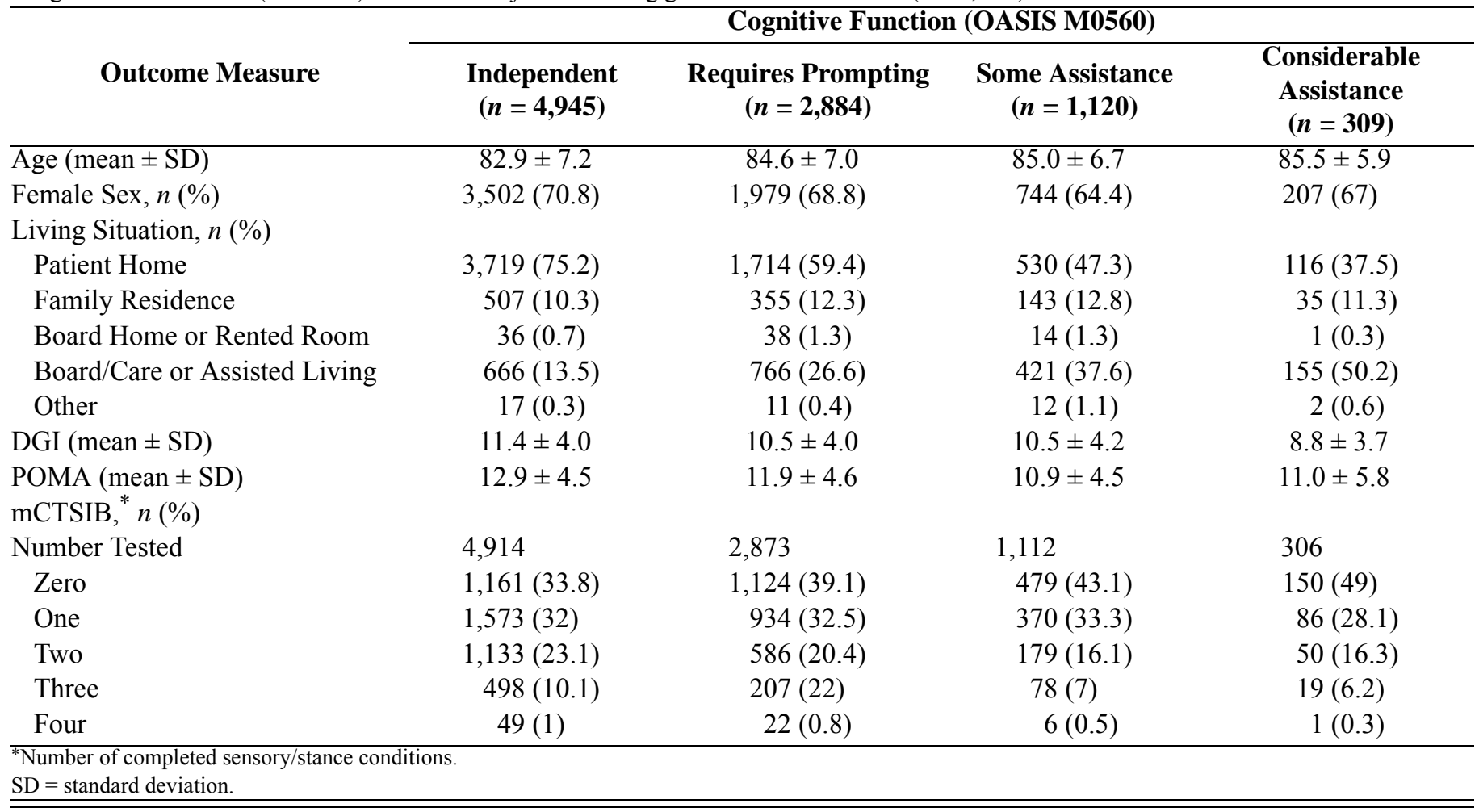

function as estimated by OASIS item M0560 are presented in Table 2. Level of cognitive function was associated with and predicted 2 percent of the variance in ageadjusted mean DGI scores $(p<0.01)$. With adjustment for age (83.2 yr), mean DGI score was independently associated with level of cognitive function group $(p<0.01)$, sex $(p<0.01)$, and standing balance as measured by the number of completed mCTSIB conditions $(p<0.01)$. This three-factor model predicted 18 percent of the variance in age-adjusted mean DGI performance. Bonferroni-adjusted pairwise comparisons in mean DGI scores showed higher mean DGI scores in the cognitively independent group (mean DGI $=12.3,95 \% \mathrm{CI}=12.0-12.6)$ compared with the group requiring prompting (mean DGI $=11.2,95 \%$ $\mathrm{CI}=10.8-11.6)$ or considerable assistance (mean DGI = 9.8, 95\% CI $=9.03-10.7)$ (all $p<0.01)$ (Figure).

Age-adjusted mean POMA scores were associated with level of cognitive function $(p<0.01)$ as measured by OASIS item M0560 (Table 2). Bonferroni-adjusted group comparisons in mean POMA scores showed significant differences between all cognitive function groups, except for patients requiring some assistance and those requiring considerable assistance. Level of cognitive function predicted 3 percent of the variance in ageadjusted POMA scores $(p<0.01)$. Mean POMA scores were also associated with standing balance performance on the mCTSIB $(p<0.01)$. Standing balance independently predicted 25 percent of the variance in mean POMA scores. Mean POMA scores increased significantly with each number of completed mCTSIB sensory/ stance conditions, except between the patients successfully completing three versus four conditions. Age was not a significant covariate, and cognitive function was not independently associated with mean POMA score when standing balance performance on the MCTSIB was included in a multivariate ANCOVA.

The nominal regression analyses demonstrated that cognitive functional limitations were associated with reduced gait performance on the DGI and mobility as measured by the POMA (Table 3). After adjustment for age, sex, and performance on the MCTSIB, the likelihood of cognitive prompting relative to independence was 


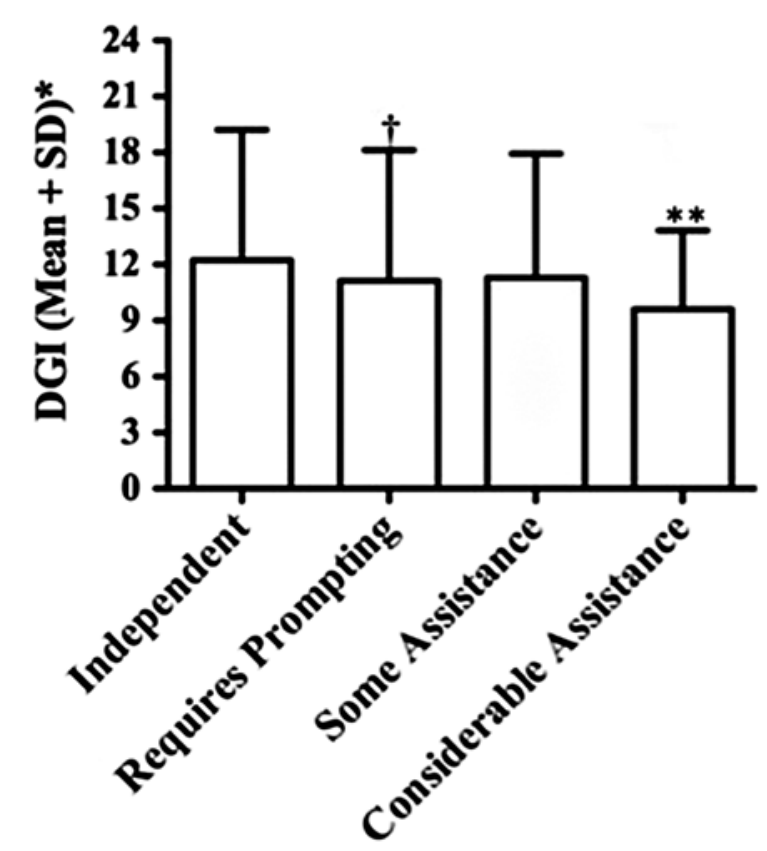

Cognitive Function (OASIS M0560)

Figure.

Age-adjusted (mean + standard deviation [SD]) Dynamic Gait Index (DGI) scores by levels of cognitive function for persons undergoing home-based health services; symbols indicate significant group differences ( $p<0.05$, Bonferroni adjusted). Significant differences existed between Considerable Assistance group and all other Outcome and Assessment Information Set (OASIS) cognitive function groups; Independent and Requires Prompting groups were significantly different. *Adjusted for age at covariate value $=83.2 \mathrm{yr}$. ${ }^{*}$ Significantly different in contrast to all other groups. ${ }^{\dagger}$ Significantly different in contrast to independent group.

reduced with each 1-point increase in both DGI $(\mathrm{OR}=$ $0.95, p<0.001)$ and POMA $(\mathrm{OR}=0.96, p<0.001)$ scores. Assistance or dependence with cognitive tasks relative to independence was likewise associated with decreasing performance on the DGI (OR $=0.93, p<$ 0.001) and the POMA $(\mathrm{OR}=0.91)$ (Table 3).

As the choice of gait measures during the clinical visit was dependent upon physical therapists' judgment, comparisons of the subject groups who were evaluated using the DGI or POMA, both measures, or none of the gait measures is important for complete understanding of patient management in this home-care clinical population. Clinician choice to administer either, both, or neither gait measure during the clinical encounter was not
Table 3.

Associations ${ }^{*}$ between Dynamic Gait Index (DGI) $(n=3,877)$ and Performance Oriented Measurement Assessment (POMA) $(n=6,154)$ measures and likelihood of Outcome and Assessment Information Set (OASIS) (M0560) cognitive functional impairment relative to independence: odds ratios with 95 percent confidence intervals (CIs).

\begin{tabular}{ccll}
\hline $\begin{array}{c}\text { Cognitive } \\
\text { Level }\end{array}$ & $\begin{array}{c}\text { Model } \\
\boldsymbol{n}\end{array}$ & Variable & $\begin{array}{l}\text { Odds Ratio } \\
\mathbf{( 9 5 \% ~ C I ) ~}\end{array}$ \\
\hline Requires Prompting & 1,120 & DGI & $0.95(0.93-0.97)$ \\
& 2,000 & POMA & $0.96(0.95-0.97)$ \\
Assistance Required & 489 & DGI & $0.93(0.91-0.95)$ \\
to Dependent & 1,038 & POMA & $0.91(0.90-0.93)$ \\
\hline
\end{tabular}

*Adjusted for age, sex, and modified Clinical Test of Sensory Integration and Balance.

related to patient age or sex. The choice to administer a gait evaluation was associated with standing balance as measured by the mCTSIB $(p<0.01)$, with patients who were able to complete none or one mCTSIB condition more likely to receive a gait evaluation using either the DGI or POMA (but not both measures).

Patients who required some assistance with cognitive function as determined by OASIS M0560 were significantly more likely to receive a gait evaluation using a single measure (versus both or neither measure, $p<0.01$ ). Patient residence was associated with the choice to administer a gait measure $(p<0.03)$. Patients living in boarding with care or assisted living settings were least likely to receive a gait evaluation using the DGI or POMA. In summary, clinicians were more likely to administer a single gait measure to patients requiring some assistance with cognitive function and having the lowest levels of standing balance function. Among patients to whom one gait measure was administered $(n=$ $8,485)$, the DGI was used by physical therapists 36.6 percent of the time $(n=3,104)$. Patients to whom the DGI was administered were younger by $1 \mathrm{yr}(p<0.01)$, were more likely to be living in their own home, and were less likely to be in an assisted setting $(p<0.01)$ than those who were tested using the POMA. Patients who were tested using the DGI were more likely to be rated at the independent level of cognitive function $(p<0.01)$.

\section{DISCUSSION}

There was a strong relationship between cognition and performance measures of gait and balance/mobility collected by physical therapists, regardless of living situation. 
Gait performance as measured by the DGI and mobility as measured by the POMA were independently associated with requiring cognitive prompting by worse scores on the gait measures. Assistance or dependence with cognitive tasks was also associated with the inability to perform any portion of the mCTSIB. This is the first study to our knowledge to find a relationship between cognition and standard measures of gait performance in older adults undergoing physical therapy services in the home.

The difference in DGI scores between the cognitively intact and the considerable assistance groups was 2.5 points. These people in the home all had very impaired gait; all mean scores for all four groups were below a mean of 11.4 out of 24 points.

Other measures of gait performance have been shown to be associated with cognitive impairment. Five and seven percent, respectively, of variance in gait speed was predicted by standard measures of cognitive function (the Trail Making-Part B and the Stroop Interference tests) in community-living older adults with mild cognitive decline [25]. Although the relationship between cognition and gait performance is statistically significant in our study, the clinical importance of our findings is difficult to interpret as there is little to no data in the literature that describes these relationships in the home healthcare practice setting.

Our findings show a 2 percent prediction in variance in DGI score due to cognitive function and a 7 percent reduction in likelihood of cognitive independence for every 1-point change in DGI. The OASIS measure of cognitive function is a 4-level scale, unlike many other more precise measures of cognitive function. There was a difference of 2.5 DGI points between the group of people rated as cognitively independent and those who required cognitive assistance after adjustment for age, sex, and standing balance. A 3-point change is considered a clinically meaningful change in persons living in the community who have higher functional performance levels [26]. Further investigation is required to explain the clinical significance of the association between cognition and gait performance in people receiving home-care services.

Patients typically referred to home-care services have difficulty walking and also may have cognitive dysfunction. If patients walked well, they would be seen in an outpatient setting for care. The minimal clinically important difference (MCID) has not been previously identified in the home-care population, so it is impossible to determine whether the MCID has been reached, but the difference of 2.5 may be clinically important in patients with limited gait function.

Therapist choice of gait measure appeared to be affected by the patients' cognition, with patients who were more cognitively aware asked to perform the DGI. As part of the DGI, four items have three or more commands that must be remembered in order to perform the gait task correctly. The physical therapists appear to have selected people with higher cognitive functioning to perform the DGI.

A minimal detectable change at the 95 percent CI for the POMA and the DGI has been reported as a 3- and a 2-point change, respectively [27]. The mean difference between the POMA scores of those who were independent and those who required considerable assistance was 1.9 (minimal detectable change is 3 ). The differences on the POMA did not exceed the minimal detectable change. For the DGI, the mean difference in the independent group versus the considerable assistance group was 2.6 (minimal detectable change score is 2). Because the DGI requires more complex, multistep commands, it is no surprise that those who required cognitive prompting would have lower scores on the DGI than the POMA. Although we did not examine change over time, it appears that the DGI might be more responsive to variations in cognitive status than the POMA.

Walking (gait) is important for maintaining functional independence. While reliant on the functioning of peripheral organs such as the musculoskeletal system, vestibular apparatus, and cardiovascular fitness, normal gait performance also depends on cortical input. Walking is the most common form of physical activity among older adults [28], is increasingly being examined as a means of health promotion and disease prevention, and has been suggested as being protective for cognitive health [9]. Although there is evidence that walking may be protective of cognitive status, there are findings that suggest that walking speed can also be used as a determinant of cognitive function [29]. It has been demonstrated in community-based studies in older adults that cognitive decline and dementia are strongly associated with higher risk of developing subsequent slow gait speed, especially in advanced states [30-31], and lower frequency of walking in the neighborhood [9]; also, decreases in cognition and gait speed have been found to be parallel over time [32-34].

Gait performance as assessed by the DGI and the POMA suggests that our homebound sample had gait and 
balance impairments. As expected, average DGI and POMA scores indicated that the subjects were at risk for falling because of subject selection, as they were referred to the home-care program based on their increased risk for falls at onset of their episode of care [16-17]. Gait speed may be an early marker of subsequent cognitive impairment [34]. Changes in coordination, finger tapping speed, and time to walk $30 \mathrm{ft}$ may be attributable to pathological processes associated with cognitive decline [35]. Our study also supports these findings that walking performance and cognition are related in a large sample of people receiving care in their homes.

Several mechanisms might explain the relationship between slow walking speed and subsequent decline in cognitive function. One possible mechanism is that walking speed could be a marker of brain lesions (white matter disease) that are associated with future cognitive decline [32]. Progression of these small white matter lesions could produce abnormalities in walking speed early in the process of decline, and only later might impairments in cognition be detected [32]. Periventricular white matter hyper intensities (high signal) on magnetic resonance imaging (MRI) scans and increased ventricular volume, even in apparently healthy older adults, have also been associated with slowing of walking speed [36]. These central nervous system changes contribute to important markers of aging [35]. More recently, changes on MRI scans in conjunction with presence of apolipoprotein E epsilon 4 predicted future cognitive decline and poor physical function in 444 older adults over a 10 yr period. Radiological findings in conjunction with apolipoprotein E epsilon 4 may single out a group at higher risk for dementia [37]. Cognitive decline and poor physical function are risk factors for disability in old age and were related in our sample.

Cognitive impairment has been considered to be a negative prognostic factor for successful rehabilitation and functional recovery [38]. Lower scores on the MMSE have also been associated with poorer physical performance on tests of gait speed, chair stand, and maximal inspiratory pressure and predicted $2 \mathrm{yr}$ declines in physical performance on a summary measure of gait speed, chair stand, and standing balance tests [33]. Successful execution of a physical task demands cognitive processes regardless of the nature of the task. Researchers using performance-based measures of physical functioning should pay particular attention to the cognitive capacities of their subjects because these might influence their assessment [34]. Cognition and physical performance in persons undergoing home-care interventions should be further studied with longitudinal follow-up in order to improve current knowledge on the effect of cognitive decline on gait/balance performance.

\section{CONCLUSIONS}

There was a strong relationship between the cognition score on the OASIS and gait/balance performance in persons undergoing home-care interventions in the home. Changes in performance may be related to cognitive decline.

\section{ACKNOWLEDGMENTS}

\section{Author Contributions:}

Study concept and design: S. L. Whitney, G. F. Marchetti, L. Otis. Acquisition of data: L. Otis.

Analysis and interpretation of the data: G. F. Marchetti.

Drafting of manuscript: S. L. Whitney, G. F. Marchetti, J. Ellis,

L. Otis, F. Asiri, A. Alghadir.

Critical revision of the manuscript for important intellectual content:

S. L. Whitney, G. F. Marchetti, J. Ellis, L. Otis.

Study supervision: S. L. Whitney.

Financial Disclosures: We are thankful to Gentiva Health Services, Atlanta, Georgia, for providing the data and opening up their database to allow us to publish regardless of the findings.

Funding/Support: This material was unfunded at the time of manuscript preparation.

Institutional Review: The University of Pittsburgh Biomedical Institutional Review Board approved the study.

Participant Follow-Up: The authors have no plans to notify the study subjects of the publication of this article because their data were provided to the authors as de-identified data; therefore, it is impossible to contact them about the results of the study.

\section{REFERENCES}

1. Alfaro-Acha A, Al Snih S, Raji MA, Markides KS, Ottenbacher KJ. Does 8-foot walk time predict cognitive decline in older Mexicans Americans? J Am Geriatr Soc. 2007; 55(2):245-51. [PMID:17302662]

http://dx.doi.org/10.1111/j.1532-5415.2007.01039.x

2. Avery E, Kleppinger A, Feinn R, Kenny AM. Determinants of living situation in a population of community-dwelling and assisted living-dwelling elders. J Am Med Dir Assoc. 2010;11(2):140-44. [PMID:20142070] http://dx.doi.org/10.1016/j.jamda.2009.07.006 
3. Studenski S, Perera S, Patel K, Rosano C, Faulkner K, Inzitari M, Brach J, Chandler J, Cawthon P, Connor EB, Nevitt M, Visser M, Kritchevsky S, Badinelli S, Harris T, Newman AB, Cauley J, Ferrucci L, Guralnik J. Gait speed and survival in older adults. JAMA. 2011;305(1):50-58. [PMID:21205966] http://dx.doi.org/10.1001/jama.2010.1923

4. Chang M, Cohen-Mansfield J, Ferrucci L, Leveille S, Volpato S, de Rekeneire N, Guralnik JM. Incidence of loss of ability to walk 400 meters in a functionally limited older population. J Am Geriatr Soc. 2004;52(12):2094-98.

[PMID:15571549]

http://dx.doi.org/10.1111/j.1532-5415.2004.52570.x

5. Lundin-Olsson L, Nyberg L, Gustafson Y. "Stops walking when talking" as a predictor of falls in elderly people. Lancet. 1997;349(9052):617. [PMID:9057736] http://dx.doi.org/10.1016/S0140-6736(97)24009-2

6. Morghen S, Gentile S, Ricci E, Guerini F, Bellelli G, Trabucchi M. Rehabilitation of older adults with hip fracture: cognitive function and walking abilities. J Am Geriatr Soc. 2011;59(8):1497-1502. [PMID:21797828] http://dx.doi.org/10.1111/j.1532-5415.2011.03496.x

7. Mangione KK, Craik RL, Palombaro KM, Tomlinson SS, Hofmann MT. Home-based leg-strengthening exercise improves function 1 year after hip fracture: a randomized controlled study. J Am Geriatr Soc. 2010;58(10):1911-17. [PMID:20929467] http://dx.doi.org/10.1111/j.1532-5415.2010.03076.x

8. Okamoto N, Nakatani T, Morita N, Saeki K, Kurumatani N. Home-based walking improves cardiopulmonary function and health-related QOL in community-dwelling adults. Int J Sports Med. 2007;28(12):1040-45. [PMID:17525884] http://dx.doi.org/10.1055/s-2007-965073

9. Prohaska TR, Eisenstein AR, Satariano WA, Hunter R, Bayles CM, Kurtovich E, Kealey M, Ivey SL. Walking and the preservation of cognitive function in older populations. Gerontologist. 2009;49(Suppl 1):S86-93. [PMID:19525221] http://dx.doi.org/10.1093/geront/gnp079

10. United States General Accounting Office. Medicare home health care Oasis data use, cost, and privacy implications [Internet]. Washington (DC): U.S. General Accounting Office; 2001 Jan. 39 p. Report No.: GAO-01-205. Available from: http://www.gao.gov/new.items/d01205.pdf

11. Rubenstein LZ. Falls in older people: epidemiology, risk factors and strategies for prevention. Age Ageing. 2006; 35(Suppl 2):ii37-41. [PMID:16926202] http://dx.doi.org/10.1093/ageing/af1084

12. Lord SR, Menz HB, Sherrington C. Home environment risk factors for falls in older people and the efficacy of home modifications. Age Ageing. 2006;35(Suppl 2):ii55-59.

\section{[PMID:16926207]}

http://dx.doi.org/10.1093/ageing/afl088

13. Hainsworth T. The role of exercise in falls prevention for older patients. Nurs Times. 2004;100(18):28-29.

[PMID:15151003]

14. Agrawal Y, Carey JP, Della Santina CC, Schubert MC, Minor LB. Disorders of balance and vestibular function in US adults: data from the National Health and Nutrition Examination Survey, 2001-2004. Arch Intern Med. 2009; 169(10):938-44. [PMID:19468085]

http://dx.doi.org/10.1001/archinternmed.2009.66

15. Glass J, Lanctôt KL, Herrmann N, Sproule BA, Busto UE. Sedative hypnotics in older people with insomnia: metaanalysis of risks and benefits. BMJ. 2005;331(7526):1169. [PMID: 16284208$]$ http://dx.doi.org/10.1136/bmj.38623.768588.47

16. Tinetti ME. Performance-oriented assessment of mobility problems in elderly patients. J Am Geriatr Soc. 1986;34(2): 119-26. [PMID:3944402]

17. Shumway-Cook A, Baldwin M, Polissar NL, Gruber W. Predicting the probability for falls in community-dwelling older adults. Phys Ther. 1997;77(8):812-19.

[PMID:9256869]

18. Shumway-Cook A, Woollacott MH. Motor control: Theory and practical applications. 1st ed. Baltimore (MD): Williams and Wilkins; 1995.

19. Shumway-Cook A, Horak FB. Assessing the influence of sensory interaction of balance. Suggestion from the field. Phys Ther. 1986;66(10):1548-50. [PMID:3763708]

20. Wrisley DM, Whitney SL. The effect of foot position on the modified clinical test of sensory interaction and balance. Arch Phys Med Rehabil. 2004;85(2):335-38.

[PMID:14966723]

http://dx.doi.org/10.1016/j.apmr.2003.03.005

21. Whitney SL, Hudak MT, Marchetti GF. The dynamic gait index relates to self-reported fall history in individuals with vestibular dysfunction. Journal of Vestibular ResearchEquilibrium \& Orientation. 2000;10(2):99-105. [PMID:10939685]

22. Di Fabio RP, Seay R. Use of the "fast evaluation of mobility, balance, and fear" in elderly community dwellers: validity and reliability. Phys Ther. 1997;77(9):904-17. [PMID:9291948]

23. Marchetti GF, Whitney SL, Blatt PJ, Morris LO, Vance JM. Temporal and spatial characteristics of gait during performance of the Dynamic Gait Index in people with and people without balance or vestibular disorders. Phys Ther. 2008; 88(5):640-51. [PMID:18292216] http://dx.doi.org/10.2522/ptj.20070130

24. Shumway-Cook A, Gruber W, Baldwin M, Liao S. The effect of multidimensional exercises on balance, mobility, 
and fall risk in community-dwelling older adults. Phys Ther. 1997;77(1):46-57. [PMID:8996463]

25. McGough EL, Logsdon RG, Kelly VE, Teri L. Functional mobility limitations and falls in assisted living residents with dementia: physical performance assessment and quantitative gait analysis. J Geriatr Phys Ther. 2013;36(2):78-86.

[PMID:22976811]

http://dx.doi.org/10.1519/JPT.0b013e318268de7f

26. Hall CD, Herdman SJ. Reliability of clinical measures used to assess patients with peripheral vestibular disorders. J Neurol Phys Ther. 2006;30(2):74-81. [PMID:16796772] http://dx.doi.org/10.1097/01.NPT.0000282571.55673.ed

27. Whitney SL, Marchetti GF, Ellis JL, Otis L. Improvements in balance in older adults engaged in a specialized home care falls prevention program. J Geriatr Phys Ther. 2013; 36(1):3-12. [PMID:22573005] http://dx.doi.org/10.1519/JPT.0b013e3182550ea5

28. Voukelatos A, Merom D, Rissel C, Sherrington C, Watson $\mathrm{W}$, Waller K. The effect of walking on falls in older people: the 'Easy Steps to Health' randomized controlled trial study protocol. BMC Public Health. 2011;11(1):888.

[PMID:22115340] http://dx.doi.org/10.1186/1471-2458-11-888

29. Liu-Ambrose T, Davis JC, Nagamatsu LS, Hsu CL, Katarynych LA, Khan KM. Changes in executive functions and self-efficacy are independently associated with improved usual gait speed in older women. BMC Geriatr. 2010;10:25. [PMID:20482830] http://dx.doi.org/10.1186/1471-2318-10-25

30. Waite LM, Broe GA, Grayson DA, Creasey H. Motor function and disability in the dementias. Int J Geriatr Psychiatry. 2000;15(10):897-903. [PMID:11044871] http://dx.doi.org/10.1002/10991166(200010)15:10<897::AID-GPS215>3.0.CO;2-C

31. Allan LM, Ballard CG, Burn DJ, Kenny RA. Prevalence and severity of gait disorders in Alzheimer's and nonAlzheimer's dementias. J Am Geriatr Soc. 2005;53(10): 1681-87. [PMID:16181166] http://dx.doi.org/10.1111/j.1532-5415.2005.53552.x

32. Rosano C, Simonsick EM, Harris TB, Kritchevsky SB, Brach J, Visser M, Yaffe K, Newman AB. Association between physical and cognitive function in healthy elderly: the health, aging and body composition study. Neuroepidemiology. 2005;24(1-2):8-14. [PMID:15459503] http://dx.doi.org/10.1159/000081043
33. Malmstrom TK, Wolinsky FD, Andresen EM, Miller JP, Miller DK. Cognitive ability and physical performance in middle-aged African Americans. J Am Geriatr Soc. 2005; 53(6):997-1001. [PMID:15935023] http://dx.doi.org/10.1111/j.1532-5415.2005.53318.x

34. Tabbarah M, Crimmins EM, Seeman TE. The relationship between cognitive and physical performance: MacArthur Studies of Successful Aging. J Gerontol A Biol Sci Med Sci. 2002;57(4):M228-35. [PMID:11909888] http://dx.doi.org/10.1093/gerona/57.4.M228

35. Camicioli R, Howieson D, Oken B, Sexton G, Kaye J. Motor slowing precedes cognitive impairment in the oldest old. Neurology. 1998;50(5):1496-98. [PMID:9596020] http://dx.doi.org/10.1212/WNL.50.5.1496

36. Sudarsky L, Ronthal M. Gait disorders among elderly patients. A survey study of 50 patients. Arch Neurol. 1983; 40(12):740-43. [PMID:6625987] http://dx.doi.org/10.1001/archneur.1983.04050110058009

37. Carmelli D, DeCarli C, Swan GE, Kelly-Hayes M, Wolf PA, Reed T, Guralnik JM. The joint effect of apolipoprotein E epsilon4 and MRI findings on lower-extremity function and decline in cognitive function. J Gerontol A Biol Sci Med Sci. 2000;55(2):M103-9. [PMID:10737693] http://dx.doi.org/10.1093/gerona/55.2.M103

38. Landi F, Bernabei R, Russo A, Zuccalà G, Onder G, Carosella L, Cesari M, Cocchi A. Predictors of rehabilitation outcomes in frail patients treated in a geriatric hospital. J Am Geriatr Soc. 2002;50(4):679-84. [PMID:11982668] http://dx.doi.org/10.1046/j.1532-5415.2002.50162.x

Submitted for publication June 23, 2012. Accepted in revised form January 30, 2013.

This article and any supplemental material should be cited as follows:

Whitney SL, Marchetti GF, Ellis J, Otis L, Asiri F, Alghadir A. Relationship between cognition and gait performance in older adults receiving physical therapy interventions in the home. J Rehabil Res Dev. 2013:50(8): 1089-98.

http://dx.doi.org/10.1682/JRRD.2012.06.0119

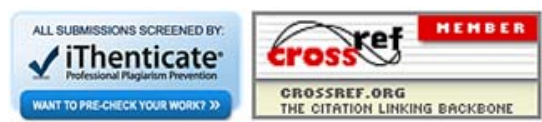


